\title{
STRESSORS AND PARENTAL COGNIZANCE ON MODULAR LEARNING MODALITY
}

\author{
Victoria B. Ornopia ${ }^{1}$, Ma. Melanie N. Edig ${ }^{2}$, Ronald S. Decano ${ }^{3}$ \\ ${ }^{1}$ Graduate Student, Doctor of Philosophy in Educational Management, Davao del Norte State College \\ ${ }^{2}$ Faculty, Institute of Advanced Studies, Davao del Norte State College \\ ${ }^{3}$ Dean, Institute of Advanced Studies, Davao del Norte State College
}

Article DOI: $\underline{\text { https://doi.org/10.36713/epra9176 }}$

DOI No: 10.36713/epra9176

\begin{abstract}
The factors are contributing to optimal parental educational involvement always intrigued to research, and the researcher wanted to dig into the issue or the problem behind the different scenarios. A wide range of stressors and parental cognizance on modular learning modality, including the home environment, socio-economic status of the family, and learning at home with a descriptive equivalent of very extensive, indicates that stressors on modular learning modality are always evident. On the other hand, the extent of parental cognizance, considered with the indicators: participation in social organizations, school programs involvement, and community collaboration with a descriptive equivalent of extensive which frequently means evident. A student's ability to succeed academically as well as cultivate a lifetime passion for learning is greatly enhanced when parents are actively involved in the lives of their kids. Furthermore, the results of this study awaken to Department of Education to maintain seminars about improving parental cognizance and training about the different modalities for the parents to develop their supporting teaching skills and deeper relationships with their children.
\end{abstract}

KEYWORDS: Stressors, modular learning modality, parental cognizance-

\section{INTRODUCTION}

The extent to which parents are involved in their children's education at home, it has been assumed, may not only depend on the quality of schools and teachers that may be a catalyst of good education, but also it could be useful shortly.

In the framework of the world. For example, as cited by (Saleem, 2020), the United States of America is also experiencing this problem due to the lack of time parents have to participate in their children's learning development. As a result, students become more exposed to technology, which makes them less inclined to study. In addition, academic failure has been connected to risky conduct and bad consequences, such as drug addiction, criminality, and emotional and behavioral difficulties, among others (Saleem,2020).

In the national context, this poses validity issues as parents are measured against standards that may not reflect their experiences and cultural beliefs. It is important to employ a cultural lens and start with an exploratory study to build a model that can help understand and examine academic involvement among the target population (Fan \& Chen, 2017). 
Parental academic involvement refers to the parent's interaction with the child and the school to promote educational success. It is a multidimensional construct that includes cognitive, affective, and behavioral facets of parenting related to children's education (Garcia 2017).

In the Philippine context, to cite some examples, measuring parents' academic involvement includes looking at parents' educational aspirations for their child, how much they feel welcomed in their child's school, and how often they read to their child (Seginer, 2017).

\section{Research Design}

\section{METHODOLOGY}

The study will use quantitative research utilizing descriptive - correlation. This design is non - experimental, which simply attempts to examine the relationship between pre-existing groups without manipulating the study's independent variable. A correlational study is a design used to investigate the strength of the association or the absence of a relationship between and among variables without manipulating or controlling any of them (Calvello, 2020 \& Bhandari, 2021). Commonly, this design has independent and dependent variables, and they are statically examined to determine their dependence or interdependence. This is tailored fit to the descriptive correlational study is effective because of the present variables, the independent variable "Stressors " and the dependent variable "Parental Cognizance " that the researcher may meet their perspective on both variables. In this research design, the researcher may be able to determine the relationship between the two variables. It is the most accurate design that can be used according to the topic.

\section{Research Respondents}

The respondents of this study were composed of 150 parents of learners in modular learning modality at private school of Davao City from Rizal Memorial Colleges, Inc. The inclusion criteria of the respondents must be parents/guardians of learners in a modular learning modality.

\section{Research Instrument}

A researcher-made instrument was prepared with the guidance of the thesis adviser and evaluators and was used to gather the needed data to realize the work. The questionnaire has 2 (variable) for the independent variable, focused on parental cognizance, considered the different indicators specifically; participation in social organizations, school programs involvement, and community collaboration, while the second variable focused on stressors, considered the different indicators specifically; learning at home, home environment, and socio-economic status of the family. To gather data for the independent variable, which is the Stressors and parental cognizance on modular learning modality? The development of the items of the research instrument was supplemented with concepts from the reviewed literature. A 5-point Likert scale response options was used in rating the statements of this part of the questionnaire. The attitude indicators were evaluated using the following response options for each item: 5 as very high, 4 as high, 3 moderate, 2 as low and 1 as very low. Also, the mean range of the results was analyzed using the description and interpretation as shown:

The five-point Likert scale was used in determining the Stressors and parental cognizance on modular learning modality. The research instrument had 30 items, and part 1 for the independent variable consisted of 15 items intended for 3 indicators, and part 2 which is for the dependent variable, had 15 items. The questionnaire was subjected to validity test from experts and was done in pilot testing used Cronbach Alpha Coefficient Test.

\section{Data Analysis}

Mean. This may determine the extent of stressors and parental cognizance on modular learning modality. Pearson's Product Moment Coefficient of Correlation. This tool may be used to determine the relationship between stressors and parental cognizance on modular learning modality.

Regression. This tool may be used to determine the domain of stressors that significantly influence parental cognizance on modular learning modality.

\section{RESULT AND DISCUSSION}

The stressors and parent cognizance or the teaching-learning process of their children now a day is inevitable, specifically in their experiences in modular learning modality: the study disclosed in the extent of stressors on modular learning modality in terms of home environment got the mean rating of 4.05 with the descriptive equivalent of extensive which indicates the stressors on modular learning modality in terms of the home environment is always 
evident, it was highlighted parent should model for their child every day in terms of how to interact with the people around them.

While the extent of stressor in modular learning modality in terms of socio-economic status of the. The total mean rating got 4.26 with the descriptive equivalent of extensive, which indicates the stressors on modular learning modality in terms of Socio-economic status of the family was always evident is valuable to pay attention always evident for the extent of stressors on modular learning modality in terms of learning at home, got a rating of 4.55 with the descriptive equivalent of very extensive which indicates the stressors on modular learning modality in terms of learning at home is always evident is well-practiced. It means that learning at home is parents also provide stimulation through everyday activities, games, rhymes, and language that help a child to learn. The overall average mean rating got 4.28 which is very extensive as a description indicates that the stressors on modular learning modality are very well practiced and always evident. It means that the stressors on modular learning modality are factors that need to be considered and necessary to pay attention.

Parents have a lot of influence when it comes to their children's involvement in social groups. Parental cognizance is shown in terms of engagement in social organizations, when parents are involved with their children's school lives; pupils have the home support and information they need to not only accomplish their homework but also build a lifetime love of learning. It is neither financial position nor the prestige of the school that a kid attends that is the most reliable predictor of academic performance. The total mean rating got 4.05 with a descriptive equivalent of extensive, which indicates the stressors on modular learning modality in terms of home environment is always evident, well practiced, and frequently evident. It means that parental cognizance in terms of participation in social organizations is sometimes evident, as the participants responded, with the total mean rating of of 4.05 with the descriptive equivalent of extensive which indicates the stressors on modular learning modality in terms of home environment is always evident is well practiced, for the school programs involvement got mean rating of 3.84 with descriptive equivalent of extensive which indicates the parental cognizance in terms of school programs involvements often evident.

While parental awareness in terms of community cooperation had a mean rating of 4.04 with the descriptive equivalent of extensive, indicating that parental cognizance in terms of community collaboration is often apparent. As a result of the participants' responses, parental awareness of community participation is well exercised. The study's findings indicated that daily interactions with parents are critical for a child's growing social skill set. Parents give the earliest opportunity for a kid to build relationships, communicate, and engage.

However, the significant relationship between the between the extent stressors on modular learning modality and parental cognizance The mean of the first variable which is Stressors on modular learning is 4.28 with the standard deviation of 0.402 and the dependent variable which is Parental Cognizance got the mean rating of 3.82 mean and 0.430 standard deviation. The Pearson-R correlation result showed 0.430 which means there is a moderate positive correlation at a significant level of .000 which means a significant relationship between the stressors on modular learning and parental cognizance. It explains that if the independent variable is increasing the dependent variable will also increase. The null hypothesis must be rejected. Thus, there is a domain of stresses on the modular learning mode that substantially impacts parental awareness, namely that an atmosphere of care and attention is a strong force for a child's healthy emotional and social development. Care that is kind, responsive, consistent, and abundant in attention and good contact readily compensates for parental shortcomings. Promote social development by modeling the manners and respect with which children look to adults and parents for assistance in developing social skills and establishing paths for meaningful learning.

The stressors on modular learning modality significantly correlated to parental cognizance. The computation of the domains of stressors on modular learning modality significantly influences the parental cognizance enumerated as follows: for the stressors on modular learning modality: learning at home garnered an f-value of 4.106 with a p-value of 0.001 or significant; home environment garnered an f-value of 4.112 with a p-value of 0.005 or significant; socio-economic status of the family garnered an f-value of 5.106 with a p-value of 0.001 or significant.

Furthermore, those stressors on the modular learning modality domain significantly influence parental cognizance. It shows that the value of the regression Analysis F ratio is 27.43, with a significant level of .000. This simply implied that the stressors on modular learning modality.

On the other hand, parental cognizance significantly influenced the indicators such as participation in social organizations garnered an f-value of 4.108 with a p-value of 0.002 or significant, school programs involvement garnered an f-value of 4.112 with a p-value of 0.005 or significant, and community collaboration garnered an f-value of 4.112 with a p-value of 0.005 or significant, that consideration of this study. The decision is to reject the null 
hypothesis. This implied that a domain of stressors on modular learning modality significantly influences the parental cognizance.

\section{CONCLUSIONS AND RECOMMENDATIONS}

Based on the data gathered, about the extent of stressors on modular learning modality, considered with the different indicator "home environment" with a descriptive equivalent of extensive that the extent of stressors on modular learning modality is well-practiced and frequently evident, socio-economic status of the family with a descriptive equivalent of very extensive indicates that the stressors on modular learning modality were very well practiced and always evident, and learning at home with a descriptive equivalent of very extensive, indicates that the stressors on modular learning modality are very well practiced and always evident, the results revealed that the stressors on modular learning modality were very well practiced and always evident.

Further, implied that the extent of parental cognizance, which is extensive as a description, indicates that the parental cognizance was well-practiced and frequently evident, participation in social organizations with a descriptive equivalent of extensive that the extent of parental cognizance well-practiced and often evident, school programs involvement with a descriptive equivalent of extensive indicates that parental cognizance was wellpracticed and often evident, community collaboration with a descriptive equivalent of extensive, indicates that the Community collaboration was well practiced and frequently evident.

Hence, the results implied that the parents' cognizance was engaging parents in their children's school lives. Students have home support and knowledge to finish their assignments and develop a lifelong love of learning. In this case reactive that parental cognizance involvement in which parents communicate with school not only when there are any issues related to behaviour problems or poor grades cannot be deemed productive or proactive parental involvement.

The researcher concluded a significant relationship between the extent of stressors on modular learning and parental cognizance, as demonstrated by Pearson- $\mathrm{R}$ correlation results. There is a moderate positive correlation at a significant level of.000, indicating a significant relationship between the extent of stressors on modular learning and parental cognizance. This explains why as the independent variable increases, the dependent variable increases. The null hypothesis must be rejected.

On the other hand, on parental cognizance, considered the different indicators specifically; participation in social organizations, school programs involvement, and community collaboration, The Pearson-R correlation result showed 0.002 which means there is a moderate positive correlation at a significant level of .000 which means that there is a significant relationship between the stressors on modular learning and parental cognizance. It explains that the decision is to reject the null hypothesis.

It simply stated that there was some domain of stressor on modular learning that had a significant effect on the domain of parental cognizance, which had the same mean rating, and on the basis of other empirical evidence from previous studies of the literature, stated that the extent of parental cognizance involvement required to ensure desired impact not only on academic outcomes but also on the psychosocial development of the growing generation is subject to sociological scrutiny. Care that is kind, responsive, consistent, and abundant in attention and good contact readily compensates for parental shortcomings.

The Department of Education should maintain seminars about "Improving parental cognizance" and training about "the different modality specifically the modular learning and parents Practice" to develop their supporting teaching skills and deeper relation with their children.

This study can be used as a basis for enhancing the educational systems on developing the new normal learning modalities for parents and students for the quality education in general, and propose program to develop the learning and educational capability of Filipino parents that it can be use any time for their family seek.

School Principal. The school principal should organize a team process like monthly staff symposium on the assessment of playing their roles, employing the practice of ethics to build a positive relationship with their colleagues and build-up trust and recognized good work to all school stakeholders, especially mentions the grouped of parents. The results may provide to the school principal reliable bases in improving their supervisory services.

Teachers. Teachers should join team-building programs that could benefit to them in any possible way even virtual activity grouped as on team. This would enable them in creating positive atmosphere inside the real of work. It may help them grow more together with their colleagues. It could not just offer them fun but could also be a way to build better relationships with their co-employees and be more active in responding to parents' needs and inquiries. 
The findings would make them become aware of the strengths and weaknesses of parents in handling and teaching their children which may encourage them to exert effort and devote quality time in helping parents with guidance and assistance provided by their superiors. Teachers holding this view emphasize facilitating parents' inquiry, prefer to give parents to chance to develop solutions of problems on their own, and allow parents to play an active role in instructional activities.

Parents. Being aware of how to manage their time, struggles, hardship and challenges to cope with their experiences, and challenges on how they can surpass, may help them recognize their efforts to gain effective skills in helping children. The direct transmission view of learning, implies that a parents' role now a day's not just merely a parent, also to communicate knowledge in a clear and structured way, to explain correct solutions, to give clear and resolvable problems, and to ensure calm and concentration in studying and learning of their children.

Future Researchers. This study may be used as a reference for future if they have to venture this kind of research.

\section{ACKNOWLEDGEMENT}

Victoria B. Ornopia, the author of this piece of work, would like to express her deep thanks and appreciation to the following individuals. Study adviser and the Dean of Davao Del Norte State College's Graduate School, Dr. Ronald Decano, for his support in finishing this research. The panel of examiners who were there provided me with helpful feedback and ideas that allowed me to make significant improvements to my essay. Thanks to Dr. Mark Van Buladaco, who assisted in the finalization of this article for publication. My parents and friends have also been a source of inspiration and encouragement, therefore I'd also want to thank them. Thank you to my professors' responders, who helped me complete my work in a short period. I owe a huge debt of gratitude to God for this wonderful accomplishment, who provided the strength and wisdom I needed.

\section{REFERENCES}

1. ACT for Youth Center of Excellence. (2015). Community Collaboration. Retrieved December 5, 2019,

2. Alternatives to School. (2015). Home-Based Learning. Retrieved December 3, 2019,

3. Australian Childhood Foundation. (2015). Supporting your child's social development. Retrieved January 3, 2016,

4. Chandler Center for Community Leadership. (2015). Community Based Collaboration: Community Wellness Multiplied. Retrieved December 4, 2018

5. Cherry, K. (2018). Introduction to Research Methods. Retrieved March 15, 2011,

6. ChildTrends.(2018). Parental Involvement in Schools. Retrieved December 4, 2015, from http://www.childtrends.org/?indicators=parental-involvement-in-schools - See more at:

7. Davis, B. (2018). Environmental factors that influence social development in children. Retrieved January 2, 2016, from http://www.livestrong.com/article/550087-environmental-factors-for-social-development-in-children/

8. Dushi, G. (2015). 5 important factors that affect social development. Retrieved December 30, 2015, from http://www.preservearticles.com/2012010920294/5-important-factors-that-affects-social-development.html

9. El Nokali, N.E., Bachman, H.J. and Votruba-Drzal, E. (2017). Parent Involvement and Children's Academic and Social Development in Elementary School. Retrieved December 1, 2015, from http://www.ncbi.nlm.nih.gov/pmc/articles/PMC2973328/

10. Fitzgerald, C. (2012). How to support social development in young children. Retrieved December 31, 2015, from http://www.scilearn.com/blog/how-to-support-social-development-in-young-children

11. Grace, E. (2015). Family factors affecting social development. Retrieved January 2, 2016, from http://www.kidsdevelopment.co.uk/familyfactorsaffectingsocialdevelopment.html

12. Huitt, W. and Dawson, C. (2011). Social development: Why it is important and how to impact it. Educational Psychology Interactive. Valdosta, GA: Valdosta State University. Retrieved January 3, 2016 from http://www.edpsycinteractive.org/papers/socdev.pdf

13. Jinnah, H.A. and Walters, L.H.(2018).Including Parents in Evaluation of a Child Development Program: Relevance of Parental Involvement. Retireved December 1, 2015, from http://ecrp.uiuc.edu/v10n1/jinnah.html

14. Kepic, G.(2016). Causes and Implications of Parental Involvement in the Advising Process. Retrieved December 4, 2015, from NACADA Clearinghouse of Academic Advising Resources Web site

15. KidsHealth.org.(2015). Getting Involved at Your Child's School. Retrieved December 2, 2015,

16. Lawson, C. (2018). Social skills and school. Retrieved December 30, 2015, from http://www.cdl.org/articles/socialskills-and-school/

17. Make Wealth History.org. (2015). Cultural and social factors that affect development. Retrieved December 31, 2015, from http://makewealthhistory.org/2007/07/01/cultural-and-social-factors-that-affect-development/ 
EPRA International Journal of Environmental Economics, Commerce and Educational Management Journal DOI: 10.36713/epra0414 |ISI I.F Value: 0.815|SJIF Impact Factor (2021): 7.743 ISSN: 2348 - 814X Volume: 8 | Issue: 12 | December 2021

18. Nix, R. (2015). Improving Parental Involvement: Evaluating Treatment Effects in the Fast Track Program. Retirved December 3, 2015, from

19. Northfolk County Council. (2015). What is Home Learning. Retrieved December 2, 2015, from http://www.norfolk.gov.uk/Childrens_services/Family_information_and_childcare/Play_and_discover_together/Home _learning/What_is_home_learning/index.htm

20. Ontario Healthy Communities Coalition. (2015). Benefits of Collaboration. Retrieved December 2, 2015, from http://www.ohcc-ccso.ca/en/courses/community-development-for-health-promoters/module-three-communitycollaboration/benefits-of-

21. Price-Mitchell, M. (2009). Boundary Dynamics: Implications for Building Parent-School Partnerships. Retrieved December 1, 2015, from http://www.adi.org/journal/fw09/Price-MitchellFall2009.pdf

22. Project Appleseed. (2014). Benefits \& Barriersto Family Involvement in Education. The National Campaign for Public School Improvement. Retrieved December 4, 2015, from

23. San Diego State University. (2015). Parent Involvement. Retrieved December 5, 2015, from http://go.sdsu.edu/education/parent/involve.aspx

24. Scan: Building Hope for Children and Families in Northern Virginia. (2015). Social development in children. Retrieved December 30, 2015, from https://www.scanva.org/support-for-parents/parent-resource-center-2/socialdevelopment-in-children/

25. Secor, S. (2016). How Environmental Factors Affect Social and Emotional Development. Retrieved January 2, 2016, from http://everydaylife.globalpost.com/environmental-factors-affect-social-emotional-development-23019.html

26. Seefeldt, C. (2010). Factors affecting social development. Pearson Allyn Bacon Prentice Hall. Retrieved January 3 , 2016, from

27. Shaw, I. (2015). Leaving School and Learning at Home. Retrieved December 4, 2015, from http://school.familyeducation.com/home-schooling/parenting/38768.html

28. Shellenbarger, S. (2019). Needed: Parent Volunteers In Schools. The Wall Street Journal. Retrieved December 3, 2015, from http://blogs.wsj.com/juggle/2011/08/31/needed-parent-volunteers-in-schools/

29. Tan-Fabian, M. (2018). Underestimating Parental Involvement. Retrieved December 3, 2015, from

30. Tomlin, C.R. (2018). Factors affecting socialization of children. Retrieved January 2, 2016, from

31. Trei, L. (2016). Academic performance and social behavior in elementary school are connected, new study shows. Retrieved December 31, 2015, from http://news.stanford.edu/pr/2006/pr-children-021506.html 